\title{
Design, implementation, and evaluation of a PRECEDE-PROCEED model-based intervention for oral and dental health among primary school students of Rafsanjan city: a mixed method study
}

\author{
Mohtasham Ghaffari ${ }^{1}$ (D), Sakineh Rakhshanderou ${ }^{1}(\mathbb{D})$, Mohammad Asadpour ${ }^{2}$ (D), Mostafa Nasirzadeh ${ }^{3 *}$ (D) and
} Leili $\operatorname{Mazar}^{4}$ (D)

\begin{abstract}
Background: Oral and dental health has a significant impact on public health as well as the quality of life among individuals and families. This study aims to design, implement, and evaluate an intervention based on the PRECEDEPROCEED model for oral and dental health among primary school students in Rafsanjan city, Southern Iran.

Methods: According to the nature of the model and with the focus group discussion and interview methods, in phases 1 to 4 (PRECEDE), predisposing, enabling, and reinforcing factors related to oral health were identified. The training program was designed and consisted of six sessions for students (250 students) with a brushing session, three sessions for parents, and two sessions for teachers. Process evaluation and the effect of the program on behavioral and factors affecting oral health were evaluated (PROCEED).
\end{abstract}

Results: In the qualitative section, seven predisposing factors, five enabling factors, and two reinforcing factors were identified. A training program based on the PRECEDE-PROCEED model was found to be effective in increasing the mean scores of the above constructs and the students' brushing behavior $(P<0.001)$.

Conclusion: Based on the model planning phases, the factors affecting the brushing behavior of children aged 6-12 years were identified. The educational program has had a significant effect on improving the scores of predisposing, enabling and reinforcing factors and children's brushing behavior.

Keywords: Oral and dental health, Brushing, PRECEDE-PROCEED model, Intervention, Primary schools' students

\footnotetext{
* Correspondence: mnasirzadeh13@rums.ac.ir

${ }^{3}$ Department of Health Education and Health Promotion, School of Health,

Occupational Environment Research Center, Rafsanjan University of Medical Sciences, Rafsanjan, Iran

Full list of author information is available at the end of the article
}

C C The Author(s). 2021 Open Access This article is licensed under a Creative Commons Attribution 4.0 International License, which permits use, sharing, adaptation, distribution and reproduction in any medium or format, as long as you give appropriate credit to the original author(s) and the source, provide a link to the Creative Commons licence, and indicate if changes were made. The images or other third party material in this article are included in the article's Creative Commons licence, unless indicated otherwise in a credit line to the material. If material is not included in the article's Creative Commons licence and your intended use is not permitted by statutory regulation or exceeds the permitted use, you will need to obtain permission directly from the copyright holder. To view a copy of this licence, visit http://creativecommons.org/licenses/by/4.0/. The Creative Commons Public Domain Dedication waiver (http://creativecommons.org/publicdomain/zero/1.0/) applies to the data made available in this article, unless otherwise stated in a credit line to the data. 


\section{Background}

Oral and dental health has a significant impact on public health as well as the quality of life among individuals and their family $[1,2]$. The World Health Organization (WHO) defines oral and dental health as " a person's status being free from any acute and chronic diseases in the mouth, teeth, face, and throat, which limit their capacity for nutrition, smile, speech, as well as mental and social health" [3].

About 99\% of people develop dental caries throughout their lives, and around 37\% of their teeth are destroyed due to caries [4]. Oral and dental diseases have been the most common diseases in humans, especially in children [5], with one out of every four preschool children in the United States suffering from tooth decay [6]. The latest results from oral and dental examinations of children aged 3 to 6 show that Iranian children pass their 3-yearold age with about 2 decayed primary teeth, and their 6year-old age with 5 decayed primary teeth [4].

Various barriers have been reported to oral and dental health among children, including high costs, low selfefficacy, fear, false beliefs about primary teeth repair, lack of cooperation and time for healthcare issues, lack of knowledge, and having a poor attitude towards oral and dental health [7-9]. Improper nutritional behavior in children, such as high sugar consumption, lack of dairy consumption, and the non-internalization of habits, such as being reluctant to brush and use dental floss lead to a high incidence of caries [10, 11]. The household's economic status [5] as well as the family's high education level promote children's oral and dental health $[12,13]$.

Children's oral and dental health is influenced by parental behavior; in addition, the interaction between family members has a positive impact on children's perception of oral and dental health [14]. Children's educational performance is highly influenced by their oral and dental health. Thus, children with poor oral and dental health are 12 times more likely than children with good oral and dental health to have restricted days, such as absenteeism [15].

Education is one of the strategies for the prevention of oral and dental diseases; hence, to achieve encouraging results, education must be principled and based on behavioral change patterns and theories [16]. The PRECEDE-PROCEED model is a planning, participatory, and community-based model widely used in planning and changing behavior and its purpose is to attract people's partnership, to utilize the specialist's view on planning, and to have a comprehensive look at the behavioral and non-behavioral determinants. This model was introduced by Green et al. and has eight phases in two parts [17], including four planning phases, one implementation phase, and three evaluation phases. The
PRECEDE part of this model stands for predisposing, reinforcing, and enabling constructs in terms of educational diagnosis and evaluation, which has an educational aspect. The PROCEED section focuses on health promotion aspects, including policies, regulations, and organizations in environmental and educational development. This model examines the causal relationship in the analysis of a health problem, but it does not measure the relationship between cause and effect and provides a clear framework for developing a behavior change plan [18].

As WHO approved the attempts to increase building capacities for education, influencing health-related behaviors namely knowledge, beliefs, skills, attitudes, values, support, and making healthy decisions, school can be one of the most suitable places for health promotion [19].

Due to the failure to achieve WHO's goals for children's oral and dental health, this study aims to design, implement, and evaluate an intervention based on the PRECEDE-PROCEED model for oral and dental health among primary school students in Rafsanjan city.

\section{Methods \\ Study setting and participants}

The present study is an exploratory sequential study consisting of two qualitative and quantitative stages conducted in 2016-2017 over a 15-month period.

In the qualitative stage, a sample of 39 volunteers, including dentists, health education and promotion professionals, parents and teachers, as well as school health educators participated through purposeful sampling with maximum variation and a semi-structured interview was conducted to determine predisposing, enabling, and reinforcing factors related to the priority identified at the third phase, data were analyzed by content analysis.

In the quantitative stage, a total of 250 students $(n=$ 122 in the intervention group and $n=128$ in the control group) studying in the primary school second grade in Rafsanjan city, were enrolled in the study. The sample size was calculated using the formula $\left(n=\left(Z_{1}+Z_{2}\right)^{2} \times\right.$ $\left.\left(2 S^{2}\right) / \mathrm{d}^{2}\right)$ considering a $10 \%$ chance of attrition. The sampling method was multi-stage cluster sampling. After coordinating to the authorities and preparing a list of schools by the executor of the project (M.N), in the first step, two girls' and boys' schools (four schools in total) considered randomly from 23 state schools (12 girls' schools and 11 boys' schools) in Rafsanjan. In the second step, based on the determined sample size and the list of students in each school, one class in each grade (fourth, fifth and sixth) was randomly selected.

\section{Study procedure and data collection}

Considering the planning essence of this model the following steps are taken corresponding to the phase number one to four: 
Table 1 Explaining the Importance of Oral Health, Inappropriate oral health, and its impact on quality of life from the perspective of literature review

\begin{tabular}{|c|c|c|}
\hline $\begin{array}{l}\text { Dimensions of } \\
\text { quality of life }\end{array}$ & Example & References \\
\hline Physical dimension & $\begin{array}{l}\text { The incidence of diseases, halitosis, speech and taste impairment, reduced growth, the risk of malnutrition, } \\
\text { sleep and smile disturbance, impairment in learning, failure to do daily homework, disorder in the game }\end{array}$ & [20-23] \\
\hline $\begin{array}{l}\text { Psychological } \\
\text { dimension }\end{array}$ & $\begin{array}{l}\text { Reduction of self-esteem and self-confidence, incidence of anxiety, stress, depression, feeling restless and } \\
\text { chaotic, dissatisfaction with mental imagery and general appearance, lack of sense of well-being and emotional } \\
\text { health, humiliation feeling, shame and embarrassment }\end{array}$ & [24-26] \\
\hline Social dimension & $\begin{array}{l}\text { Disruption of communication and social interactions, lack of social participation (like recreational programs), } \\
\text { social rejection and labeling, absence from school and work, disruptions in career and academic performance, } \\
\text { impact on the quality of family life }\end{array}$ & [27-29] \\
\hline Economic dimension & Impact on the economic situation of the family, impose economic costs & {$[30,31]$} \\
\hline
\end{tabular}

In the social assessment (phase 1), the impact of oral and dental health on the quality of life in children and their families was assessed in different aspects based on a focus group discussion with 9 stakeholders (mothers with children aged 6-12 and dentists) and the study of 13 theses, 26 Persian articles, 54 English articles, 12 books, other scientific resources, and It was found out that poor oral and dental health affects people's physical, mental, social, and economic quality of life (Table 1).

In the epidemiological, behavioral, and environmental assessment (phase 2), the major index related to the quality of life, in terms of oral and dental health, was the number of decayed, missing (extracted), and filled teeth (DMFT), and the most important of which was dental caries. Next, behavioral and non-behavioral factors were identified (Table 2) based on a focus group discussion with 9 stakeholders (mothers with children aged 6-12 and dentists), and the review of 9 theses, 36 Persian articles, 39 English articles, 8 books, other scientific resources, such as the World Health Organization. In addition, the major influential behavioral factor was determined to be brushing behavior based on the opinions of a 14 health education professionals and dentists on the basis of decision-making matrix, with two criteria of importance and variability.

In the educational and ecological assessment (phase 3), predisposing, enabling, and reinforcing factors associated with brushing behavior were identified based on a focus group discussion with 9 stakeholders (mothers with children aged 6-12 and dentists) and the study of 7 theses, 26 Persian articles, 21 English articles, books, scientific websites and documentations, and next, a qualitative study was designed aimed at better explaining the data, and semi-structured interviews were conducted with 39 stakeholders, including dentists, health education and promotion professionals, parents, teachers, and school health educators. Accordingly, the major factors affecting toothbrushing behavior were identified, and after adjusting them to the findings of the first part of this phase, the major predisposing, enabling, and reinforcing factors associated with brushing behavior were identified.

Table 2 Behavioral and non-behavioral factors affecting tooth decay based on literature review and scientific resources

\begin{tabular}{|c|c|}
\hline Behavioral factors & Non-behavioral factors \\
\hline Do not do fluoride therapy & $\begin{array}{l}\text { Person and tooth resistance (genetic factors, } \\
\text { congenital or acquired) }\end{array}$ \\
\hline Use of fluoride-free toothpaste & Fluoride in drinking water \\
\hline No use of dental floss & Age and gender \\
\hline Do not brush & Economic status and social class \\
\hline Over-consumption of sugar, sweets, and carbohydrates & Dimensions of the family \\
\hline Lack of regular referral (six months) to the dentist to receive preventive services & Parent's job and education \\
\hline Overeating and weight gain & blood type \\
\hline Reduce milk and dairy consumption & Level of salivation and concentration \\
\hline \multirow{4}{*}{$\begin{array}{l}\text { Eating snacks and unhealthy snack foods } \\
\text {-chewing Gum, Chips, Puffs, Lavashes and Salt and Nutritional Snacks- junk food }\end{array}$} & Chronic and systemic diseases \\
\hline & Residence \\
\hline & Consistency of food \\
\hline & Health literacy \\
\hline
\end{tabular}


All the executive activities of the above steps were performed by the project executor (M.N) and the actions were approved by the other members of the research team.

After adjusting the findings of the qualitative stage to those of the quantitative one, the questionnaire was formulated, face and content validity was assessed by 10 experts in health education and health promotion and pediatric dentistry, and reliability was assessed by a testretest estimate in 57 students at a 14-day interval, and the final tool was designed (Table 3). The questionnaire is available in supplementary section (Additional file 1).

In the administrative \& policy assessment and intervention alignment (phase 4), project executor (M.N), held a session at the office of the head of Rafsanjan Administration of Education, and the program was explained to the principals of the selected schools. Then, a coordination session was held separately at each school, all resources and facilities were reviewed, and pre-test was done. The results of the pre-test were analyzed, an intervention program was formulated, a coordination session with school administrators was re-arranged, and the method of implementing the intervention program was explained.

In the process evaluation phase, we evaluated the implemented program according to what we had designed, the designed program proceeded regularly, only the interviews required more time. An intervention program was run based on the findings from previous steps among students (6 training sessions and one session for brushing) aimed at promoting students' knowledge, attitude, and practice in terms of brushing by the executor of the project (M.N). The program included lectures, questions, and answers, the explaining of related experiences, practical demonstration, and role playing in learning areas and educational goals, the use of educational media, such as short videos, posters, and educational folders. Three sessions for parents and two sessions for teachers and school health educators were held aimed at enhancing their collaboration and gaining their support for sustaining students' behavior. Then, impact assessments were carried out, based on the designed method, among the students 3 months after

Table 3 The characteristics of the tools developed in three areas predisposing, enabling, and reinforcing factors

\begin{tabular}{|c|c|c|c|c|c|c|c|c|c|}
\hline Factor & Structure & $\begin{array}{l}\text { Number of } \\
\text { questions }\end{array}$ & Response scale & $\begin{array}{l}\text { How to } \\
\text { respond }\end{array}$ & $\begin{array}{l}\text { The scope of } \\
\text { questions }\end{array}$ & CVR & CVI & $\begin{array}{l}\text { Cronbach's } \\
\text { alpha }\end{array}$ & $\begin{array}{l}\text { Internal } \\
\text { correlation } \\
\text { coefficient } \\
\end{array}$ \\
\hline \multirow{2}{*}{$\begin{array}{l}\text { *Demographic } \\
\text { characteristics }\end{array}$} & & 11 & - & Self-Reporting & - & - & - & - & \\
\hline & Knowledge & 24 & multiple choice & Self-Reporting & $0-24$ & 0.95 & 0.96 & - & 0.84 \\
\hline \multirow{7}{*}{$\begin{array}{l}\text { Predisposing } \\
\text { Factors }\end{array}$} & Attitude & 7 & Three-part Likert & Self-Reporting & $7-21$ & 0.94 & 0.97 & 0.72 & \\
\hline & Perceived susceptibility & 3 & Three-part Likert & Self-Reporting & $3-9$ & 1 & 0.93 & 0.68 & \\
\hline & Perceived severity & 10 & Three-part Likert & Self-Reporting & $10-30$ & 0.96 & 0.96 & 0.90 & \\
\hline & Perceived benefits & 11 & Three-part Likert & Self-Reporting & $11-33$ & 1 & 0.99 & 0.78 & \\
\hline & Subjective norms & 3 & Three-part Likert & Self-Reporting & $3-9$ & 1 & 1 & 0.73 & \\
\hline & Observational learning & 3 & Three-part Likert & Self-Reporting & $3-9$ & 1 & 1 & 0.85 & \\
\hline & $\begin{array}{l}\text { The motivation to } \\
\text { comply }\end{array}$ & 3 & Three-part Likert & Self-Reporting & $3-9$ & 1 & 1 & 0.88 & \\
\hline \multirow{5}{*}{$\begin{array}{l}\text { Enabling } \\
\text { Factors }\end{array}$} & Perceived barriers & 6 & Three-part Likert & Self-Reporting & $6-18$ & 1 & 1 & 0.80 & \\
\hline & Self-efficacy & 5 & $\begin{array}{l}\text { Yes - to some } \\
\text { extent - no }\end{array}$ & Self-Reporting & $5-15$ & 1 & 1 & 0.78 & \\
\hline & $\begin{array}{l}\text { Perceived behavioral } \\
\text { control }\end{array}$ & 6 & $\begin{array}{l}\text { Yes - to some } \\
\text { extent - no }\end{array}$ & Self-Reporting & $6-18$ & 0.96 & 0.98 & 0.79 & \\
\hline & Behavioral preferences & 5 & Three-part Likert & Self-Reporting & - & 1 & 1 & - & \\
\hline & Brushing skill & 12 & Yes No & $\begin{array}{l}\text { Checklist- } \\
\text { Observation }\end{array}$ & $0-12$ & - & - & 0.82 & \\
\hline \multirow{4}{*}{$\begin{array}{l}\text { Reinforcing } \\
\text { Factors }\end{array}$} & Social reinforcement & 5 & Three-part Likert & Self-Reporting & $5-15$ & 1 & 1 & 0.85 & \\
\hline & Social support & 4 & Three-part Likert & Self-Reporting & $4-12$ & 1 & 1 & 0.76 & \\
\hline & Behavior & 21 & Yes- No & ${ }^{* *}$ check list- & $0-21$ & - & - & - & \\
\hline & Behavioral intention & 4 & Yes- No & Self-Reporting & $0-4$ & 0.95 & 1 & 0.82 & \\
\hline
\end{tabular}

*Demographic variables included age, sex, education, and parents' occupation, family income and oral health status

** Parents completed the checklist of behavior 
the intervention. In addition, leaflets, CDs, educational folders, toothbrushes, and toothpastes were distributed among the students as gifts.

In the brushing session, according to the correct brushing method at the last session using practical demonstration, the role-playing method, and the use of moulage, the school water supply was used, and brushing was performed in groups of 5 to 7 individuals, with the brushing behavior of each student evaluated and necessary trainings provided. The purpose of this session was to remove some barriers, such as embarrassment and low self-efficacy in some students. In this session, the school's health educator brushed with the students, thereby encouraging them to grow enthusiasm.

In the beginning of the study (phase 1) until the completion of the intervention program (the implementation phase), all activities were planned in the Gantt chart. This program was scheduled for a 12-month period, and process evaluation was carried out and reported for each activity. To do so, activities carried out at each phase were reviewed by the type of activity, its scheduling, and its implementation method, with necessary corrections made. The important point in the evaluation was the increase in the time assigned to the interviews, which were planned over 2 months, but they took 3 months due to the sampling problems. In the end, it took 12 months for this study to complete the intervention and 3 months to evaluate the effect.

\section{Statistical analyses}

Data were analyzed by SPSS version 18.0 using MannWhitney, Wilcoxon, and chi-square tests at the significance level of 0.05 .

\section{Results}

Based on the essence of model planning and according to phases one to 5 of the model, as described in the materials and methods section, an intervention program was designed and implemented; the results of the program are as follows:

According to the impact assessment, the mean age of the intervention group and that of the control group was $10.77 \pm 1.01$ and $10.98 \pm 0.88$, respectively. About 49 and $47 \%$ of the students in the intervention and control groups were girls, respectively. The results of the independent t-test and the chi-square test showed no significant difference in the variables of age, gender, parental education, parental occupation, family income, as well as oral and dental health status between the two groups $(P>$ 0.05). After implementing the intervention program, a significant difference was observed $(P<0.001)$ in the mean score and standard deviation of knowledge, attitude, perceived susceptibility, perceived severity, perceived benefits, perceived barriers, self-efficacy, perceived behavioral control, subjective norms, motivation to comply, observational learning, brushing skills, social support and reinforcement, as well as the behavioral intention of brushing in the intervention group members. In addition, the results indicated the impact of the intervention program on all predisposing, enabling, and reinforcing factors as well as proper brushing behavior (Tables 4 and 5).

\section{Discussion}

Based on the phases of the model, at the phase one, two, and three, using group discussion with mothers and professionals, as well as literature review, scholarly resources and dissertations, the importance of oral and dental health was explained, and the major index influencing the quality of life associated with oral and dental health was determined. In addition, the major behavioral factor influencing that index was identified. Next, the predisposing, enabling, and reinforcing factors associated with that factor were identified.

Similar to other studies, DMFT was the major index of the quality of life affecting oral and dental health [3234]. At the beginning of the study, $35.2 \%$ of the students brushed their teeth less than twice a day, and $64.7 \%$ of them brushed their teeth at least twice a day. In the study of Goodarzi et al., 44.7\% of students brushed their teeth less than twice a day, and in the study of John et al., $31.5 \%$ of students brushed their teeth at least twice a day $[35,36]$. After the educational intervention, 96.6\% of the students brushed their teeth at least twice a day, indicating an improvement in their brushing performance through education.

\section{Predisposing factors}

The major predisposing factors of brushing behavior included demographic characteristics, knowledge, attitude, perceived susceptibility, perceived severity, perceived benefits, subjective norms, observational learning, and motivation to comply.

Knowledge, as the first step in the behavior change process, could play a key role in this process. The major weaknesses of the students in terms of awareness were the lack of knowledge of negative consequences (lack of awareness of psychological, psychological, and social consequences, such as decreased self-esteem, embarrassment, and losing friends), not meeting oral and dental health requirements, and the presence of symptoms of dental caries. Among the students' wrong attitudes, one could refer to the lack of belief in the brushing method and benefits of toothpastes. Holding a group discussion, answering questions about the complications and symptoms of dental caries as well as improper oral and dental health, and also extracting and correcting some of the wrong attitude and beliefs led to an increase in the mean score of these constructs in the intervention group. In the study of 
Table 4 Comparison of the mean score of predisposing, enabling, and reinforcing factors before and 3 months after the intervention in two groups

\begin{tabular}{|c|c|c|c|c|c|}
\hline Factor & Structure & Group & $\begin{array}{l}\text { Before of intervention } \\
M \pm S D\end{array}$ & $\begin{array}{l}\text { After of intervention } \\
M \pm S D\end{array}$ & $P$-Value* \\
\hline \multirow[t]{24}{*}{ Predisposing Factors } & \multirow[t]{3}{*}{ Knowledge (0-24) } & Intervention & $10.48 \pm 3.37$ & $18.93 \pm 2.77$ & $<0.001$ \\
\hline & & Control & $10.40 \pm 2.98$ & $11.66 \pm 3.54$ & $<0.001$ \\
\hline & & $P$-Value** & 0.091 & $<0.001$ & \\
\hline & \multirow[t]{3}{*}{ Attitude (7-21) } & Intervention & $18.70 \pm 2.00$ & $19.82 \pm 1.99$ & $<0.001$ \\
\hline & & Control & $18.80 \pm 2.01$ & $19.01 \pm 1.81$ & 0.14 \\
\hline & & $P$-Value ${ }^{* *}$ & 0.93 & $<0.001$ & \\
\hline & \multirow[t]{3}{*}{ Perceived Susceptibility (3-9) } & Intervention & $7.41 \pm 1.45$ & $7.87 \pm 1.40$ & $<0.001$ \\
\hline & & Control & $7.45 \pm 1.49$ & $7.81 \pm 1.27$ & 0.005 \\
\hline & & $P$-Value** & 0.74 & 0.04 & \\
\hline & \multirow[t]{3}{*}{ Perceived Severity (10-30) } & Intervention & $24.11 \pm 3.89$ & $28.36 \pm 3.39$ & $<0.001$ \\
\hline & & Control & $23.00 \pm 4.22$ & $23.44 \pm 4.05$ & 0.30 \\
\hline & & $P$-Value ${ }^{* *}$ & 0.05 & $<0.001$ & \\
\hline & \multirow[t]{3}{*}{ Perceived Benefit (11-33) } & Intervention & $29.08 \pm 3.35$ & $31.95 \pm 1.96$ & $<0.001$ \\
\hline & & Control & $29.51 \pm 3.24$ & $29.41 \pm 3.21$ & 0.51 \\
\hline & & $P$-Value ${ }^{* *}$ & 0.26 & $<0.001$ & \\
\hline & \multirow[t]{3}{*}{ Subjective Norms (3-9) } & Intervention & $8.26 \pm 1.07$ & $8.65 \pm 0.83$ & $<0.001$ \\
\hline & & Control & $8.22 \pm 1.19$ & $8.19 \pm 1.20$ & 0.30 \\
\hline & & $P$-Value ${ }^{* *}$ & 0.63 & $<0.001$ & \\
\hline & \multirow[t]{3}{*}{ Motivation to Comply (3-9) } & Intervention & $7.71 \pm 1.45$ & $8.44 \pm 1.13$ & $<0.001$ \\
\hline & & Control & $7.46 \pm 1.53$ & $7.29 \pm 1.62$ & 0.23 \\
\hline & & $P$-Value** & 0.11 & $<0.001$ & \\
\hline & \multirow[t]{3}{*}{ Observational Learning (3-9) } & Intervention & $7.13 \pm 1.89$ & $8.07 \pm 1.63$ & $<0.001$ \\
\hline & & Control & $7.25 \pm 1.57$ & $6.72 \pm 1.86$ & 0.007 \\
\hline & & $P$-Value ${ }^{* *}$ & 0.94 & $<0.001$ & \\
\hline \multirow[t]{13}{*}{ Enabling Factors } & \multirow[t]{3}{*}{ Perceived Barrier (6-18) } & Intervention & $8.61 \pm 2.29$ & $7.45 \pm 2.33$ & $<0.001$ \\
\hline & & Control & $8.20 \pm 1.94$ & $8.30 \pm 2.82$ & 0.81 \\
\hline & & $P$-Value ${ }^{* *}$ & 0.25 & $<0.001$ & \\
\hline & \multirow[t]{3}{*}{ Self-Efficacy (5-15) } & Intervention & $13.29 \pm 2.29$ & $14.36 \pm 1.23$ & $<0.001$ \\
\hline & & Control & $13.18 \pm 2.22$ & $13.17 \pm 2.09$ & 0.74 \\
\hline & & $P$-Value $* *$ & 0.49 & $<0.001$ & \\
\hline & \multirow{3}{*}{$\begin{array}{l}\text { Perceived Behavioral } \\
\text { Control }(6-18)\end{array}$} & Intervention & $14.14 \pm 2.76$ & $16.37 \pm 2.16$ & $<0.001$ \\
\hline & & Control & $14.35 \pm 2.83$ & $14.42 \pm 2.93$ & 0.92 \\
\hline & & $P$-Value ${ }^{* *}$ & 0.49 & $<0.001$ & \\
\hline & \multirow[t]{4}{*}{ Tooth Brushing Skill (0-12) } & Intervention & $5.72 \pm 2.27$ & $10.72 \pm 1.75$ & $<0.001$ \\
\hline & & Control & $6.44 \pm 2.77$ & $5.59 \pm 2.15$ & 0.01 \\
\hline & & $P$-Value ${ }^{* *}$ & 0.01 & $<0.001$ & \\
\hline & & Ancova & - & $<0.001$ & \\
\hline \multirow[t]{4}{*}{ Reinforcing Factors } & \multirow[t]{4}{*}{ Social Support (4-12) } & Intervention & $9.99 \pm 2.12$ & $11.00 \pm 1.61$ & $<0.001$ \\
\hline & & Control & $9.54 \pm 2.06$ & $9.44 \pm 2.35$ & 0.72 \\
\hline & & $P$-Value $* *$ & 0.02 & $<0.001$ & \\
\hline & & Ancova & - & $<0.001$ & \\
\hline
\end{tabular}


Table 4 Comparison of the mean score of predisposing, enabling, and reinforcing factors before and 3 months after the intervention in two groups (Continued)

\begin{tabular}{|c|c|c|c|c|c|}
\hline Factor & Structure & Group & $\begin{array}{l}\text { Before of intervention } \\
M \pm S D\end{array}$ & $\begin{array}{l}\text { After of intervention } \\
M \pm S D\end{array}$ & $P$-Value* \\
\hline & Social Reinforcement (5-15) & Intervention & $12.15 \pm 2.76$ & $13.88 \pm 1.85$ & $<0.001$ \\
\hline & & Control & $12.14 \pm 2.47$ & $11.75 \pm 2.92$ & 0.14 \\
\hline & & $P$-Value** & 0.07 & $<0.001$ & \\
\hline \multirow[t]{4}{*}{ Behavior } & Intention Behavior (0-4) & Intervention & $3.19 \pm 1.27$ & $3.73 \pm 0.68$ & $<0.001$ \\
\hline & & Control & $3.74 \pm 0.67$ & $3.33 \pm 1.10$ & 0.62 \\
\hline & & $P$-Value** & 0.02 & $<0.001$ & \\
\hline & & Ancova & - & $<0.001$ & \\
\hline
\end{tabular}

*Mann Whitney U test

**Wilcoxon test

Babaee et al. on students aged 12-14 and in that of Sanadhya et al. on students aged 12-15, oral and dental health education improved the mean score of students' knowledge $[37,38]$. In the study of Shirzad et al. an educational intervention could change the attitude of mothers and teachers towards students' brushing [39].

In the present paper, by informing the students on the positive consequences of proper oral and dental health behavior as well as the negative consequences in different aspects of the quality of life, their perceived susceptibility and perceived severity improved. Peyman and Pourhaji in their study, provided an educational program based on the Health Belief Model on oral and dental health behavior, which significantly increased the scores of perceived susceptibility, perceived severity, and perceived benefits in primary school students [40]. Subjective norms are the amount of social pressure perceived by an individual to perform a behavior; in other words, it is the reflection of the social influence on the individual, along with motivation to comply, which can cause to behavioral intention [18]. After the intervention program, the difference between the mean score of subjective norms and that of motivation to comply was significant between the two groups, indicating that the intervention program increased the mean score of these two constructs. In the study by Naseri-Salahshour et al. an oral and dental health promotion program aimed at preventing early dental caries in schoolchildren led to a significant increase in subjective norms after educational intervention [41].

\section{Enabling factors}

The major enabling factors associated with brushing behavior included perceived barriers, self-efficacy, perceived behavioral control, and the ability to brush or brushing skills.

Gum bleeding and numbness were the major perceived barriers in the present study. The mean score of perceived barriers decreased significantly by a group discussion, questions and answers, as well as the explaining of the importance of oral and dental health and its effects on general health. In the study of Hajimiri et al. oral and dental health education in mothers of children aged 3-6 in terms of tooth decay, based on the Health Belief Model in Zanjan city, significantly reduced the perceived barriers score [42]. Such a statistically significant difference was also observed in the study of Shamsi et al. on pregnant women in Arak [43].

Table 5 Comparison of frequency distribution of brushing behavior of students before and after intervention in two groups

\begin{tabular}{|c|c|c|c|c|c|c|}
\hline \multirow{2}{*}{$\begin{array}{l}\text { Daily } \\
\text { toothbrush } \\
\text { behavior }\end{array}$} & \multirow[t]{2}{*}{ Group } & \multicolumn{2}{|c|}{ Before intervention } & \multicolumn{2}{|c|}{ After intervention } & \multirow[t]{2}{*}{$P$-Value } \\
\hline & & Number & Percentage & Number & Percentage & \\
\hline \multirow[t]{3}{*}{ Less than once } & Intervention & 27 & 22.1 & 1 & 0.82 & $<0.001$ \\
\hline & Control & 16 & 12.5 & 14 & 11.02 & 0.09 \\
\hline & $P$-Value & 0.03 & & $<0.001$ & & \\
\hline \multirow[t]{3}{*}{ One to two times } & Intervention & 16 & 13.1 & 3 & 2.4 & $<0.001$ \\
\hline & Control & 30 & 23.4 & 27 & 21.2 & 0.08 \\
\hline & $P$-Value & 0,04 & & $<0.001$ & & \\
\hline \multirow[t]{3}{*}{ Twice and more } & Intervention & 79 & 64.7 & 117 & 96.6 & $<0.001$ \\
\hline & Control & 0.03 & 64 & 86 & 67.6 & 0.08 \\
\hline & $P$-Value & $<0.001$ & & $<0.001$ & & \\
\hline
\end{tabular}


The concept of self-efficacy in the present study was students' confidence in the ability to correct brushing behavior after each meal, between meals, and even after eating sweets. The mean score of self-efficacy after the intervention was $95.73 \%$, which was significantly higher than that before the intervention. Consistent with the present study, in the study of Ghorbaniet al. the mean score of the self-efficacy of oral and dental healthpromoting behavior increased significantly after an educational intervention [44]. According to the results of some studies, poor self-efficacy among students regarding oral and dental health care behavior is one of the main causes of tooth decay and loss $[45,46]$. In another study, an increase in self-efficacy in oral and dental health behavior encouraged parents to arrange preventive dental visits for their children [47].

In the present study, perceived behavioral control was defined as the students' ability to display brushing behavior in situations, such as on trips, during an illness, in the state of boredom, when attending school, or when not having a toothpaste. The intervention program was shown to be effective in promoting their ability. Makvand et al. developed an effective oral and dental health interventional program to enhance perceived behavioral control in mothers of children aged 1-2 [48].

In the present study, the mean score of the brushing skill was $47.2 \%$ before the intervention. The percentage of this construct was $89.3 \%$ after the intervention, which was significantly higher than that before the intervention. In the study of Levin et al. the intervention program significantly increased the brushing skill from 26.1 to $87.7 \%$ [49].

In the present study, the students' behavioral intention scores increased significantly after the educational intervention. In the study by Ebrahimipour et al. oral and dental health education based on the theory of planned behavior increased the behavioral intention score of pregnant women from $17.3 \pm 2.5$ to $21.4 \pm 2$ [50]. Behavioral preferences were the major effective variables in displaying brushing behavior, so it is suggested that parents consider children's behavioral preferences. According to the perspective of the experts in the qualitative research, the behavioral preferences of children, such as brushing outside the toilet, having a colorful and attractive toothbrush, being able to choose toothbrushes and toothpastes, and brushing with parents must be taken into consideration.

\section{Reinforcing factors}

The most important reinforcing factors identified in this study were social support and social reinforcement. By holding training classes for parents, teachers, and school educators, we sought to guide, assist, remind, and encourage the students to brush their teeth on a regular basis.

\section{Conclusions}

Based on phases one to three of the model, the major predisposing factors identified in this study were knowledge, attitude, perceived susceptibility, perceived severity, perceived benefits, subjective norms, observational learning, and motivation to comply. Constructs, such as perceived barriers, proper brushing skills, perceived behavioral control, and behavioral preferences were the enabling factors. In addition, the constructs of social reinforcement and social support were the reinforcing factors based on the findings of the qualitative part of the study.

In phases four and five, the educational program was designed and implemented. According to the sixth and seventh phases, process and impact were performed. The results of the intervention indicate that, intervention program based on the community-based participatory PRECEDE-PROCEED planning model was effective in promoting tooth-brushing behavior, as well as predisposing, enabling, and reinforcing factors. Therefore, considering the importance of planning and its role in the effectiveness of intervention programs, it is suggested that participatory planning patterns such as, the PRECEDE-PROCEED model, be used in designing intervention programs.

\begin{abstract}
Abbreviations
PRECEDE: Predisposing, reinforcing and enabling constructs in educational diagnosis and evaluation; PROCEED: Policy, regulatory, and organizational constructs in educational and environmental development
\end{abstract}

\section{Supplementary Information}

The online version contains supplementary material available at https://doi. org/10.1186/s12889-021-11585-z.

Additional file 1. Questionnaire.

\begin{abstract}
Acknowledgements
The authors would like to express their appreciation to the Rafsanjan and Shahid Beheshti University of Medical Sciences authorities, the Ministry of Education, teachers and principals, and students who contributed on this research.
\end{abstract}

\begin{abstract}
Authors' contributions
M.G and S. R conceptualized, designed, and managed the study. M. N conducted focus group discussions and interviews in the phases 1 to 4, and implemented intervention programs in phase 5. M. G and S. R study and confirm the findings of each phase, they were supervisors and consultants during the implementation process. M. G and M. N evaluated the program in later phases. M. N, M. A and L. M were involved in drafting the manuscript. M. G and S. R critically revised the manuscript for important intellectual content. All authors read and approved the final manuscript.
\end{abstract}

Funding

The present study financially supported by the Vice Chancellery for Research and Technology of Rafsanjan University of Medical Sciences and Shahid Beheshti University of Medical Sciences. The funders had no role in the study design, data collection, data analysis, data interpretation and writing the manuscript or the decision to submit for publication. 


\section{Availability of data and materials}

The datasets generated and analyzed during the current study are available from the corresponding author on a reasonable request through an E-mail (mnasirzadeh13@yahoo.com).

\section{Declarations}

\section{Ethics approval and consent to participate}

This study, derived from the results of the collaborative research project between the Vice Chancellors for Research and Technology at Rafsanjan University of Medical Sciences (Code 350) and Shahid Beheshti University of Medical Sciences (Code 8555) and it was approved by Ethics Committee of Rafsanjan University of Medical Sciences (NO: IR.RUMS.REC.1395.42). Written informed consent were obtained from all participants' parents and all interviews were audiotape and transcribed with participant's consent.

\section{Consent for publication}

Not applicable.

\section{Competing interests}

The authors declare that they have no competing interests.

\section{Author details}

'Department of Public Health, School of Public Health and Safety, Shahid Beheshti University of Medical Sciences, Tehran, Iran. ${ }^{2}$ Department of Health Education and Health Promotion, School of Health, Rafsanjan University of Medical Sciences, Rafsanjan, Iran. ${ }^{3}$ Department of Health Education and Health Promotion, School of Health, Occupational Environment Research Center, Rafsanjan University of Medical Sciences, Rafsanjan, Iran. ${ }^{4}$ Department of Health Education and Health Promotion, School of Health, Student Research Committee, Rafsanjan University of Medical Sciences, Rafsanjan, Iran.

Received: 10 July 2020 Accepted: 2 August 2021

Published online: 03 September 2021

\section{References}

1. AbdAllah EA, Metwalli NE, Badran AS. Effectiveness of a one-year oral health educational and preventive program in improving oral health knowledge and oral hygiene practices of a group of autistic Egyptian children and their caregivers. Fut Dent J. 2018;4(1):23-9. https://doi. org/10.1016/j.fdj.2018.02.001.

2. Ghaffari M, Rakhshanderou S, Nasirzadeh M, Asadpour M. Oral health behaviors and related quality of life among 12 years old Rafsanjan children, 2017-18. J Kerman Univ Med Sci. 2019;26:420-9.

3. World Health Organization, Oral health, key facts. https://www.who.int/ news-room/fact-sheets/detail/oral-health. Accessed 3 Apr 2019.

4. Goodarzi A, Tavaffian SS, Heidarnia AR, Ziaoddini H. Health literacy and oral health in primary school students of district of 14 in Tehran, Iran. Mil Caring Sci. 2016. https://doi.org/10.18869/acadpub.mcs.2.4.229.

5. Esmailikia M, Gholami A, Abedzadeh MS, Sayehmiri K, Ghazanfari Z. Predict of oral health status of 3-6 years old children of llam: based on health belief model. J llam Uni Med Sci. 2016:24:49-58.

6. Mattheus D. Efficacy of Oral health promotion in primary care practice during early childhood: creating positive changes in Parent's Oral health beliefs and behaviors. Oral Health Dent Manag. 2014;13(2):316-9.

7. Shirzad M, Taghdisi MH, Dehdari T, Abolghasemi J. The effect of educational intervention in changing mothers' attitudes, perceived self-efficacy and perceived barriers regarding Oral health of preschool children. Iran J Health Educ Health Promot. 2015;3:181-7.

8. Ghaffari M, Nasirzadeh M, Rakhshanderou S, Ramezankhani A. Some of the strongest predisposing factors on the behavior of tooth brushing among iranian school age children. Int J Pediatr. 2017. https://doi.org/10.22038/ijp.2 017.22660.1892.

9. Ghaffari M, Nasirzadeh M, Rakhshanderou S, Ramezankhani A. Unacceptable status of oral and dental health-related knowledge among Iranian primary school students. Biosci Biotechnol Res Commun. 2017;10:260-6.

10. Keikhaee R, Rakhshani F, Izadi S, Hashemi Z. Survey of oral health behaviors and its associated factors in female students of primary schools in Zabol based on health belief model. J Zabol Univ Med Sci Health Serv. 2012:4:3341 Persian.
11. Nishide S, Yoshihara T, Hongoud H, Kanehirad T, Yawakaa Y. Daily life habits associated with eveningness lead to a higher prevalence of dental caries in children. J Dent Sci. 2019;14(3):302-8. https://doi.org/1 0.1016/j.jds.2019.01.015.

12. Matsuo F, Sato S, Moriyama M. The effect of parents' oral health behaviors on children and mutual communication. Pediatr Dent J. 2016;26(3):122-8. https://doi.org/10.1016/j.pdj.2016.09.002.

13. Kasmaei P, Amin Shokravi F, Hidarnia A, Hajizadeh E, Atrkar RZ. Survey of predictive factors on brushing behavior according to the three main motivational constructs among female students of primary schools. J Guilan Univ Med Sci. 2014;23:16-22

14. Kabiry B, Shakerinejad G, Karami KB, Angalli KA. The Effect of Training on Students' Oral and Dental Health Behaviors and Health Belief Model Constructs. Sadra Med Sci J. 2017;2:327-38 Persian.

15. Guarnizo-Herreño CC, Lyu W, Wehby GL. Children's Oral health and academic performance: evidence of a persisting relationship over the last decade in the United States. Pediatrics. 2019;209:183-189.e2. https://doi. org/10.1016/j.jpeds.2019.01.045.

16. Safari M, Shojaeizadeh D, Gofrani F, Heidarnia A, Hajipakpour A. Theories, models and health education and promotion: Asar Sobhan Publications; 2014. p. 35-8.

17. Zareban E, Ezadirad H, Adineh HA. Health Educational theory and model. Tehran: Modal Science and technology; 2018. p. 53-65.

18. Glanz K, Rimer BK, Viswanath K. Health behavior and health education: theory, research, and practice: John Wiley \& Sons; 2015.

19. World Health Organization. Health promoting schools, Focus. https://www. who.int/health-topics/health-promoting-schools\#tab=tab_2. Accessed 18 Mar 2021.

20. Nilchian F, Jabbarifar SE, Larijani M, Navaei H. Evaluation of the impact of children's oral health on their family quality of life in Amol, Iran. J Isfahan Dent Sch. 2013;8(7):662-8 [In Persian].

21. Reissmann DR, John MT, Schierz O, Kriston L, Hinz A. Association between perceived oral and general health. J Dent. 2013;41(7):581-9. https://doi. org/10.1016/jj.jdent.2013.05.007.

22. Mohebbi SZ, Sheikhzadeh S, Bayanzadeh M, Batebizadeh A. Impact on daily performance (OIDP) index in patients attending patients Clinic at Dentistry School of Tehran University of Medical Sciences. J Dent Med Tehran Univ Med Sci. 2012;25(2):135-41 [In Persian].

23. Uonesian F, Shahroudi E, Kavand K, Dorri M, Akbarzadeh-Bagheban E, Khoshnevisan MH. Oral health-related quality of life in children 11 to 14 years old Iran by the child-OIDP index, section II-tooth social impacts (sociodental impact) periodontal disease and caries. J Dent Sch Shahid Beheshti Univ Med Sci. 2010;28(4):225-31 [In Persian].

24. Mazaheri R, Ahmadi Roozbahani N, Jabarifar SE, Birjandi N, Bayat H. Evaluation of oral health status in 8-11-year-old primary school students of Isfahan and its effect on their family. J Isfahan Dent Sch. 2012;8(2):151-61 [In Persian].

25. Saleki M, Jabarifar SE, Soheilipour S, Hajizadeh F. Assessing the sensitivity and responsiveness of Early Childhood Oral Health Impact Scale to routine dental treatments on life quality of preschool children in Isfahan in 2011. J Isfahan Dent Sch. 2012;7(5):688-97 [In Persian].

26. Weissbluth Frejman M, Ardenghi Vargas I, Kuchenbecker Rösing C, Quadrado CL. Dentofacial deformities are associated with lower degrees of self-esteem and higher impact on Oral health-related quality of life: results from an observational study involving adults. J Oral Maxillofac Surg. 2013; 71(4):763-7. https://doi.org/10.1016/.joms.2012.08.011.

27. Navab Azam A, Haji Ahmadi M, Falah Zade H, Haeriyan A, Tavakoli E, Moshkel GH. Relationship between Quality of Life and Oral Health Status within 14-18 Year-Old Male Students in Yazd. YJDR. 2015;4(2):522-31 [Persian].

28. Khadem P, Jabarifar E, Maroofi V, Ghasemi D, Mohammad Taher V. The Relationship between Oral and dental health and quality of life based on DIDL index. J Res Dent Sci. 2011;7(4):41-35 [Persian].

29. Choi ES, Lyu J, Kim HY. Association between oral health status and health related quality of life (EuroQoL-5 dimension). J Dent Hyg Sci. 2015;15(4): 480-7. https://doi.org/10.17135/jdhs.2015.15.4.480.

30. Golkari A, Moeini A, Jabbarifar SE. Relationship of socioeconomic status with quality of life related to oral and dental health of 25-year-olds in shiraz. J Isfahan Dent Sch. 2014;9(6):534-41 [Persian].

31. Scarpelli AC, Paiva SM, Viegas CM, Carvalho AC, Ferreira FM, Pordeus IA. Oral health-related quality of life among B razilian preschool children. Community Dent Oral Epidemiol. 2013:41(4):336-44. https://doi.org/10.1111/ cdoe.12022. 
32. Goodarzi A, Heidarnia A, Tavafian SS, Eslami M. Evaluation of decayed, missing and filled teeth (DMFT) index in the 12 years old students of Tehran city, Iran. Braz J Oral Sci. 2019. https://doi.org/10.20396/bjos.v17i0. 8654061 Persian.

33. Marasouli P, Mohammadi Khoshrou M, Hoseinzadeh M, Niknejad E. Survey of $\mathrm{dmft}$ and $\mathrm{dmft}$ indices in urmia orphanages in 6-18-year-old individuals in 2014. J Urmia Univ Med Sci. 2016;27:729-34.

34. Makan R, Gara M, Awwad MA, Hassona Y. The oral health status of Syrian refugee children in Jordan: an exploratory study. Spec Care Dent. 2019;39(3): 306-9. https://doi.org/10.1111/scd.12377.

35. Goodarzi A, Heidarnia A, Tavafian SS, Eslami M. The survey of oral-dental health of elementary school students of tehran city and its related factors. Mil Caring Sci. 2018. https://doi.org/10.29252/mcs.5.2.137 Persian.

36. John JR, Daniel B, Paneerselvam D, Rajendran G. Prevalence of dental caries, oral hygiene knowledge, status, and practices among visually impaired individuals in Chennai, Tamil Nadu. Int J Dent. 2017;2017:1-6. https://doi. org/10.1155/2017/9419648

37. Babaee N, Kardan K, Aghazadeh F, Nooribayat S. Effect of oral and dental hygiene education on the knowledge of caries preventive behaviors in the guidance school students. J Babol Univ Med Sci. 2012;14:83-7 Persian.

38. Sanadhya YK, Thakkar JP, Divakar DD, Pareek S, Rathore K, Yousuf A, et al. Effectiveness of oral health education on knowledge, attitude, practices and oral hygiene status among 12-15-year-old schoolchildren of fishermen of Kutch district, Gujarat, India. Int Maritime Health. 2014;65(3):99-105. https:// doi.org/10.5603/IMH.2014.0022.

39. Shirzad M, Taghdisi MH, Dehdari T, Abolghasemi J. Oral health education program among pre-school children: an application of health-promoting schools approach. Health Promot Perspect. 2016. https://doi.org/10.15171/ hpp.2016.26.

40. Peyman N, Pourhaji F. The effects of educational program based on the health belief model on the oral health behaviors of elementary school students. Mod Care J. 2015;12:74-8.

41. Naseri-Salahshour V, Abredari H, Sajadi M, Sabzaligol M, Karimy M. The effect of oral health promotion program on early dental decay in students: a theory-based study. J Caring Sci. 2019. https://doi.org/10.15171/jcs.2019.015.

42. Hajimiri $\mathrm{KH}$, Sharifirad $\mathrm{GH}$, Hasanzade A. The effect of oral health education based on health belief model in mothers who had 3-6-year-old children on decreasing dental plaque index in Zanjan. J Adv Med Biomed Res. 2010;18: 77-86 Persian

43. Shamsi M, Hidarnia A, Niknami S, Rafiee M, Zareban I, Karimy M. The effect of educational program on increasing oral health behavior among pregnant women: applying health belief model. Health Educ Health Promot. 2014; $1(2): 21-36$.

44. Ghorbani B, Shahnazi H, Hassanzadeh A. Improving student's self-efficacy and perceived susceptibility toward oral and dental health: a randomized controlled trial. Oman Med J. 2018;33(5):423-8. https://doi.org/10.5001/omj.2 018.77 .

45. Shahnazi H, Hosseintalaei M, Esteki Ghashghaei F, Charkazi A, Yahyavi Y, Sharifirad G. Effect of educational intervention on perceived susceptibility self-efficacy and dmft of pregnant women. Iran Red Crescent Med J. 2016; 18(5):e24960. https://doi.org/10.5812/ircmj.24960.

46. SohrabiVafa M, Moeini B, Hazavehei MM, Soltanian AR. The effect of education based on health belief model (HBM) in decreasing dental plaque index among first grade of middle- school girl students in Hamadan. J Urmia Nurs Midwifery Fac. 2013;11(8):639-47 Persian.

47. Askelson NM, Chi D, Momany ET, Kuthy RA, Carter KD, Field K, et al. The importance of efficacy: using the extended parallel process model to examine factors related to preschool-age children enrolled in medicaid receiving preventive dental visits. Health Educ Behav. 2015. https://doi.org/1 $0.1177 / 1090198115580575$.

48. Makvandi Z, Karimi-Shahanjarini A, Faradmal J, Bashirian S. Evaluation of an oral health intervention among mothers of young children: a clustered randomized trial. J Res Health Sci. 2015;15(2):88-93.
49. Levin L, Bilder L, Borisov O. Improving oral hygiene skills among children undergoing treatment at the haemato-oncology department-an interventional programme. Int Dent J. 2015;65(4):211-5. https://doi.org/1 $0.1111 /$ idj.12171.

50. Ebrahimipour S, Ebrahimipoiur H, Alibakhshian F, Mohamadzadeh M. Effect of education based on the theory of planned behavior on adoption of oral health behaviors of pregnant women referred to health centers of Birjand in 2016. J Int Soc Prev Comm Dent. 2016. https://doi.org/10.4103/22310762.195514.

\section{Publisher's Note}

Springer Nature remains neutral with regard to jurisdictional claims in published maps and institutional affiliations.

\section{Ready to submit your research? Choose BMC and benefit from:}

- fast, convenient online submission

- thorough peer review by experienced researchers in your field

- rapid publication on acceptance

- support for research data, including large and complex data types

- gold Open Access which fosters wider collaboration and increased citations

- maximum visibility for your research: over $100 \mathrm{M}$ website views per year

At BMC, research is always in progress.

Learn more biomedcentral.com/submissions 